\title{
Mussel-inspired human gelatin nanocoating for creating biologically adhesive surfaces
}

This article was published in the following Dove Press journal:

International Journal of Nanomedicine

29 May 2014

Number of times this article has been viewed

Xi Yang',2
Liping Zhu'
Seiichi Tada'
Di Zhou'
Takashi Kitajima'
Takashi Isoshima'
Yasuhiro Yoshida ${ }^{1,4}$
Mariko Nakamura ${ }^{1,5}$
Weiqun Yan ${ }^{2}$
Yoshihiro Ito',3
'Nano Medical Engineering
Laboratory, RIKEN, Saitama,
Japan; ${ }^{2}$ School of Pharmaceutical
Sciences, Jilin University, Jilin,
People's Republic of China;
${ }^{3}$ Emergent Bioengineering Materials
Research Team, RIKEN Center for
Emergent Matter Science, Saitama,
${ }^{4}$ Department of Biomaterials and
Bioengineering, Graduate School of
Dental Medicine, Hokkaido University,
Hokkaido, ${ }^{5}$ Dental Hygiene
Program, Kibi International
College, Okayama, Japan

Correspondence: Yoshihiro Ito Nano Medical Engineering Laboratory, RIKEN, 2-I Hirosawa, Wako-shi, Saitama 35I-0198, Japan

Email y-ito@riken.jp

\begin{abstract}
Recombinant human gelatin was conjugated with dopamine using carbodiimide as a surface modifier. This dopamine-coupled human gelatin (D-rhG) was characterized by ${ }^{1} \mathrm{H}$-nuclear magnetic resonance, mass spectroscopy, and circular dichroism. D-rhG-coated surface properties were analyzed by physicochemical methods. Additionally, cell attachment and growth on the modified surfaces was assessed using human umbilical endothelial cells. Binding of gelatin onto titanium was significantly enhanced by dopamine conjugation. The thickness of the D-rhG coating depended on the treatment $\mathrm{pH}$; thicker layers were formed at higher $\mathrm{pH}$ values, with a maximum thickness of $30 \mathrm{~nm}$. D-rhG enhanced the binding of collagen-binding vascular endothelial growth factor and cell adhesion as compared with gelatin alone, even at the same surface concentration. The D-rhG surface modifier enhanced substrate binding by creating an adhesive nanointerface that increased specific protein binding and cell attachment.
\end{abstract}

Keywords: recombinant human gelatin, dopamine, natural catechols, cell adhesion, cell culture, titanium

\section{Introduction}

Modification of the surfaces of materials used for cell culture and tissue engineering is often necessary to provide suitable material surface environments for contact with cells and tissues. ${ }^{1,2}$ Gelatin coating is widely used for surface modification. Gelatin is a mixture of peptides and proteins produced by partial hydrolysis of collagen extracted from the skin, bone, and connective tissue of a number of different animals, including domesticated cattle, chicken, pigs, and fish. However, human gelatin or collagen is required for medical applications.

Therefore, recombinant methods of producing human gelatin or collagen have been recently developed and investigated. ${ }^{3}$ Olsen et al prepared low molecular weight recombinant human gelatin using yeast, ${ }^{4}$ Duan et al reported an expression system for hydroxylated gelatin using Pichia pastoris, ${ }^{5}$ Shoseyov et al developed a technique to generate recombinant human collagen from a genetically engineered tobacco plant, ${ }^{6}$ and Adachi et al used transgenic silkworms to produce recombinant human gelatin by introducing a type I collagen $\alpha 1$ chain gene that encompassed the entire triple helical region. ${ }^{7}$

We have modified recombinant human gelatin to expand its functions and applications. For example, gelatin modified with cholesterol was prepared as nanosized gel particles, ${ }^{8,9}$ and photoreactive gelatin was prepared to covalently immobilize gelatin itself and to coimmobilize other biological molecules on various types of organic materials. ${ }^{10}$ However, immobilization of gelatin to inorganic materials, which 
is employed for replacement of hard tissues such as bone, joints, and teeth, remains difficult. ${ }^{11,12}$

Biomimetic approaches inspired by mussel adhesive activity have recently been devised to modify inorganic materials with biological molecules. Because of its location in the active site of mussel adhesive protein, the importance of the catechol structure of 3,4-dihydroxyphenylalanine (DOPA) has been recognized. Dopamine (3,4-dihydroxyphenethylamine), which has a similar structure, has been used by many researchers as a surface treatment to prepare organic layers, even on inorganic surfaces. ${ }^{13-20}$ Further, dopamine has been attached to synthetic polymers, derivatives of which are used for surface modification of metals. ${ }^{21-23}$ These treatments not only provide organic layers, but also increase immobilization of biological molecules on the surfaces of various materials. ${ }^{24-33}$

Various methods for dopamine conjugation have been investigated, including direct chemical coupling with polysaccharides. Hyaluronic acid, heparin, and $\beta$-cyclodextrin have been conjugated with dopamine or DOPA to increase the adhesiveness of the original polysaccharides. ${ }^{34-38}$

To extend its applications, we modified human recombinant gelatin ( $\mathrm{rhG}$ ) using dopamine to create a universal surface modifier that can even be used for metal surfaces. We characterized this molecularly defined, recombinantly prepared biopolymer in detail, and examined its biological adhesiveness using a collagen-binding growth factor $^{39}$ and human umbilical endothelial cells (HUVECs). Titanium was used as the treated inorganic material because of its widespread application in many biomedical devices. ${ }^{32,33,40,41}$

\section{Materials and methods Materials \\ Proteins}

The rhG was produced by transgenic silkworms and purified from their cocoons in the manner described by Adachi et al. ${ }^{7}$ A fusion protein consisting of the fibronectin collagen binding domain and vascular endothelial growth factor (CBD-VEGF) was prepared as described previously. ${ }^{39}$

\section{Cells}

HUVECs were obtained from Lonza (Basel, Switzerland) and expanded in EGM2 medium (Lonza) containing 5\% fetal bovine serum, antibiotics, insulin-like growth factor, ascorbic acid, hydrocortisone, and angiogenic factors, including basic fibroblast growth factor, epidermal growth factor, and vascular endothelial growth factor (VEGF).

\section{Substrates}

Titanium-coated glass discs (15 $\mathrm{mm}$ in diameter) were prepared as previously reported. ${ }^{40,41}$

\section{Chemicals}

3,4-Dihydroxyphenethylamine hydrochloride (dopamine) and N-hydroxysuccinimide were purchased from Wako Pure Chemical Industries (Osaka, Japan). 1-Ethyl-3-(3-dimethylaminopropyl)-carbodiimide hydrochloride (water-soluble carbodiimide) was obtained from Dojindo Molecular Technologies, Inc., (Kumamoto, Japan).

\section{Modification of gelatin}

rhG was conjugated with dopamine as shown in Figure 1. Lyophilized rhG (350 mg) was dissolved in $60 \mathrm{~mL}$ of 2-(N-morpholino)ethanesulfonic acid buffer $(50 \mathrm{mM}$, $\mathrm{pH} 4.5$ ) and mixed with $150 \mathrm{mg}$ of $\mathrm{N}$-hydroxysuccinimide, $191 \mathrm{mg}$ of water-soluble carbodiimide, and $103 \mathrm{mg}$ of dopamine. The mixture was stirred for 48 hours in the dark at $40^{\circ} \mathrm{C}$. The resulting solution was dialyzed against deionized water and lyophilized to obtain a dopamine-conjugated human gelatin (D-rhG). The yield was $206 \mathrm{mg}$ (59\%).

\section{Surface treatment}

The surface of the titanium discs was washed in hexane solution, cleaned with $6 \mathrm{M}$ hydrogen chloride for 10 minutes, rinsed twice with triple distilled water, dried in a vacuum oven for 24 hours, and cleaned photochemically using an Excimer ultraviolet lamp (Ushio Inc., Tokyo, Japan) for 10 minutes before surface treatment, as reported previously. ${ }^{40,41}$

To treat the surfaces with rhG or D-rhG, each solution was pipetted onto the titanium surface and allowed to stand for

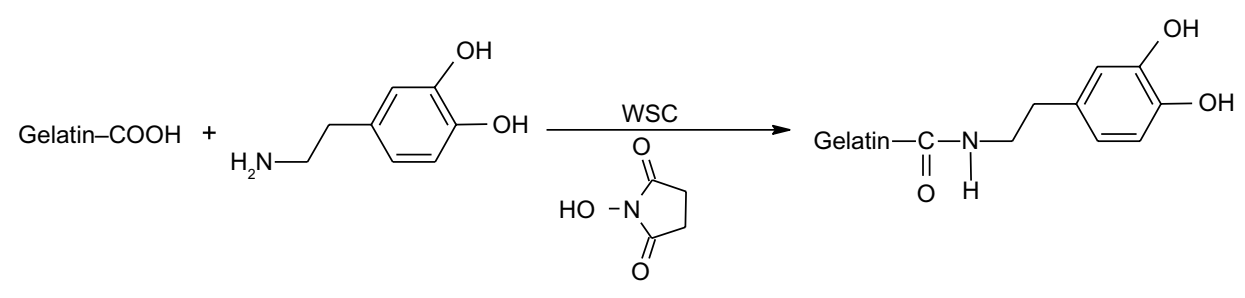

Figure I Schematic diagram showing the synthesis of dopamine-conjugated recombinant human gelatin. 
12 hours at $37^{\circ} \mathrm{C}$ in a moist chamber. Following incubation, the discs were washed three times with phosphate-buffered saline.

\section{Characterization of modified gelatin}

${ }^{1} \mathrm{H}$-nuclear magnetic resonance measurements were performed on a JEOL 400 instrument (JEOL Ltd, Tokyo, Japan). Mass spectroscopy measurements were performed using a QSTAR Elite device (Applied Biosystems, Life Technologies, Carlsbad, CA, USA) for matrix assisted laser desorption/ionization time-of-flight mass spectrometry in the Support Unit for Bio-Materials Analysis Research Resources Center at the RIKEN Brain Science Institute.

Circular dichroism measurements were performed using a J-720 spectrophotometer (Jasco, Tokyo, Japan). Sample volumes of $250 \mu \mathrm{L}(0.01 \mathrm{wt} \%)$ were measured using a $1 \mathrm{~mm}$ cuvette (scan type, continuous; scan speed, $100 \mathrm{~nm}$ per minute; response time, $2.0 \mathrm{sec}$; bandwidth, $1.0 \mathrm{~nm}$ ). Each sample was measured twice and average spectra were obtained. Turbidity measurements were performed using $100 \mu \mathrm{L}$ of sample $(0.03 \mathrm{wt} \%)$ on a $\mathrm{V}-550$ spectrophotometer (Jasco) at a wavelength of $500 \mathrm{~nm}$.

\section{Surface characterization}

The surface atomic composition was analyzed by X-ray photoelectron spectroscopy (AXIS-HS, Kratos, Manchester, UK) under vacuum conditions of less than $10^{-7} \mathrm{~Pa}$. Al-K $\alpha$ monochromatic X-rays with a power source of $150 \mathrm{~W}$ were used. Scans were acquired at pass energies of $80 \mathrm{eV}$ (wide) and $40 \mathrm{eV}$ (narrow). Overview spectra were obtained in the range of $0-1,100 \mathrm{eV}$ using analyzer pass energies of $80 \mathrm{eV}$ and $40 \mathrm{eV}$.

Surface wettability was determined by observing the water contact angle on the discs. First, $10 \mu \mathrm{L}$ droplets of water were placed on the discs (untreated and treated titanium), and images of the droplets were then captured 5 seconds after placement. The water contact angle was measured at $25^{\circ} \mathrm{C}$ using a contact-angle meter (Kyowa Interface Science Co, Tokyo, Japan). All contact angles were determined by averaging ten different point values measured on each surface.

The thickness of the polymer was measured using an M-2000UI ellipsometer (JA Woollam Co, Lincoln, NE, USA) in the spectral range of $245-1,500 \mathrm{~nm}$ at three different incident angles $\left(50^{\circ}, 60^{\circ}\right.$, and $\left.70^{\circ}\right)$.

The surface morphology of the samples was observed using an MPD-3D atomic force microscope (Asylum Research, Co, Goleta, CA, USA). The images were taken in $\mathrm{AC}$ (noncontact) mode using an atomic force microscope tip (NCH-W, NanoWorld AG, Neuchatel, Switzerland) in dry atmospheric pressure conditions.

\section{Binding assay of gelatin}

The binding of gelatin to the titanium surface was measured at $25^{\circ} \mathrm{C}$ using a quartz crystal microbalance with dissipation monitoring (Meiwafosis Co, Tokyo, Japan). First, Milli-Q water (Millipore Corporation, Billerica, MA, USA) was allowed to run until the baseline stabilized. Next, the sample was run for 3 minutes at $65 \mu \mathrm{L}$ per minute. The pump was then turned off for 15 minutes, after which the substrate was washed in running Milli-Q water. At least three measurements were performed and the average value was calculated.

\section{Growth factor binding assay}

The treated titanium discs were incubated with a solution of fusion protein, CBD-VEGF $(2 \mu \mathrm{g} / \mathrm{mL}$, based on the VEGF concentration) for 12 hours at $4^{\circ} \mathrm{C}$ and then washed with phosphate-buffered saline. The amount of VEGF bound to the gelatin was determined using an anti-VEGF mouse monoclonal antibody (R\&D Systems, Minneapolis, MN, USA) as follows. The discs were rinsed with phosphatebuffered saline-Tween $(0.2 \% \mathrm{v} / \mathrm{v})$, blocked in an aqueous solution of nonfat milk $(4 \% \mathrm{w} / \mathrm{v})$ for 30 minutes, washed again three times with phosphate-buffered saline-Tween $(0.2 \% \mathrm{v} / \mathrm{v})$, and incubated with an anti-VEGF antibody (1:500) overnight at $4^{\circ} \mathrm{C}$. After incubation with a secondary antibody (anti-mouse IgG) labeled with fluorescein isothiocyanate (GE Healthcare, Little Chalfont, UK) for one hour at room temperature, the surface images were taken on an AxioObserver fluorescent microscope equipped with an AxioCam MRc5 camera (Carl Zeiss Co, Ltd, Göttingen, Germany). The amount of bound CBD-VEGF was measured by AxioVision 4.8 digital image software (Carl Zeiss) on the images of the disc surfaces. To make calibration curves, various known concentrations of the secondary antibody conjugated with fluorescein isothiocyanate were spotted on the surface of titanium and treated similarly.

\section{Cell culture}

HUVECs maintained in EGM2 medium at $37^{\circ} \mathrm{C}$ in $95 \%$ humidified air $/ 5 \% \mathrm{CO}_{2}$ were recovered by trypsinization and resuspended in fresh medium for the following experiments.

For the cell attachment assay, titanium discs treated with rhG and D-rhG were washed, sterilized with ethanol and phosphate-buffered saline, and placed in 24-well tissue culture plates. The suspension of HUVECs was added 

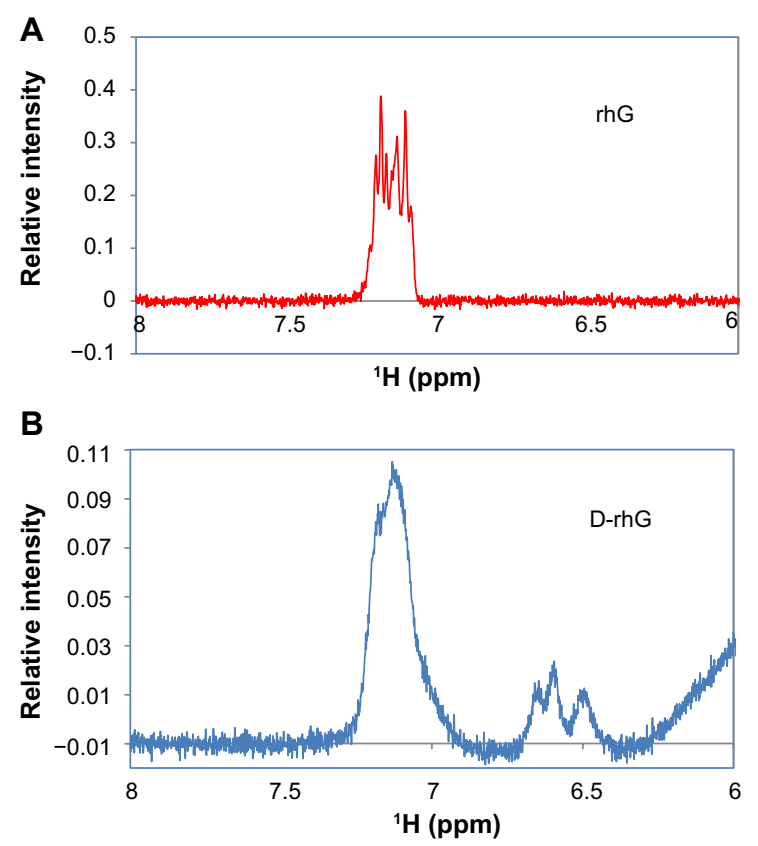

Figure 2 ' $\mathrm{H}$ nuclear magnetic resonance spectra of (A) rhG and (B) D-rhG. Abbreviations: rhG, recombinant human gelatin; D-rhG, dopamine-coupled human gelatin.

to the treated titanium discs and the cells were incubated in EGM2 medium for 30 minutes. After removal of the unattached cells, the number of attached cells was counted under a phase-contrast microscope (CKX 41, Olympus, Tokyo, Japan).

For the cell growth assay, HUVECs were recovered in basal culture medium (EBM2, Lonza) with 1\% fetal bovine serum but without angiogenic factors. The cell suspension was added to D-rhG-treated or rhG-treated titanium discs after binding with CBD-VEGF as prepared above. The culture medium was changed every 2 days, and after 5 days of culture, cell proliferation was assessed by a cell counting kit (WST8, Dojindo Molecular Technologies, Inc.) using the method described by Ishiyama et al. ${ }^{42}$

\section{Statistical analysis}

Independent experiments were performed at least three times. Triplicate samples were analyzed in each experiment and representative data are shown. The significance of the data obtained from the control and treated groups was statistically assessed by paired Student's $t$-tests, with $P$-values less than 0.05 considered to be statistically significant.

\section{Results and discussion Characterization of modified gelatin}

The nuclear magnetic resonance spectrum of D-rhG showed benzene ring peaks included in the dopamine at 6-7 ppm (Figure 2). Based on the integration of the peaks, approximately five dopamine groups were conjugated with each rhG. However, the molecular weight of unmodified gelatin was $89,612 \mathrm{Da}$ and that of modified gelatin was 90,634 Da (Figure 3). The difference in the weights $(1,022 \mathrm{Da})$ between the modified and unmodified gelatins corresponded to 6.7 dopamine molecules (152 Da). Both measurements indicate that five or six dopamine groups were conjugated in the D-rhG.

Considering that there are 36 lysine groups in $\mathrm{rhG}$, about $15 \%$ of the lysine groups in $\mathrm{rhG}$ were used for the conjugation. Circular dichroism spectra showed no

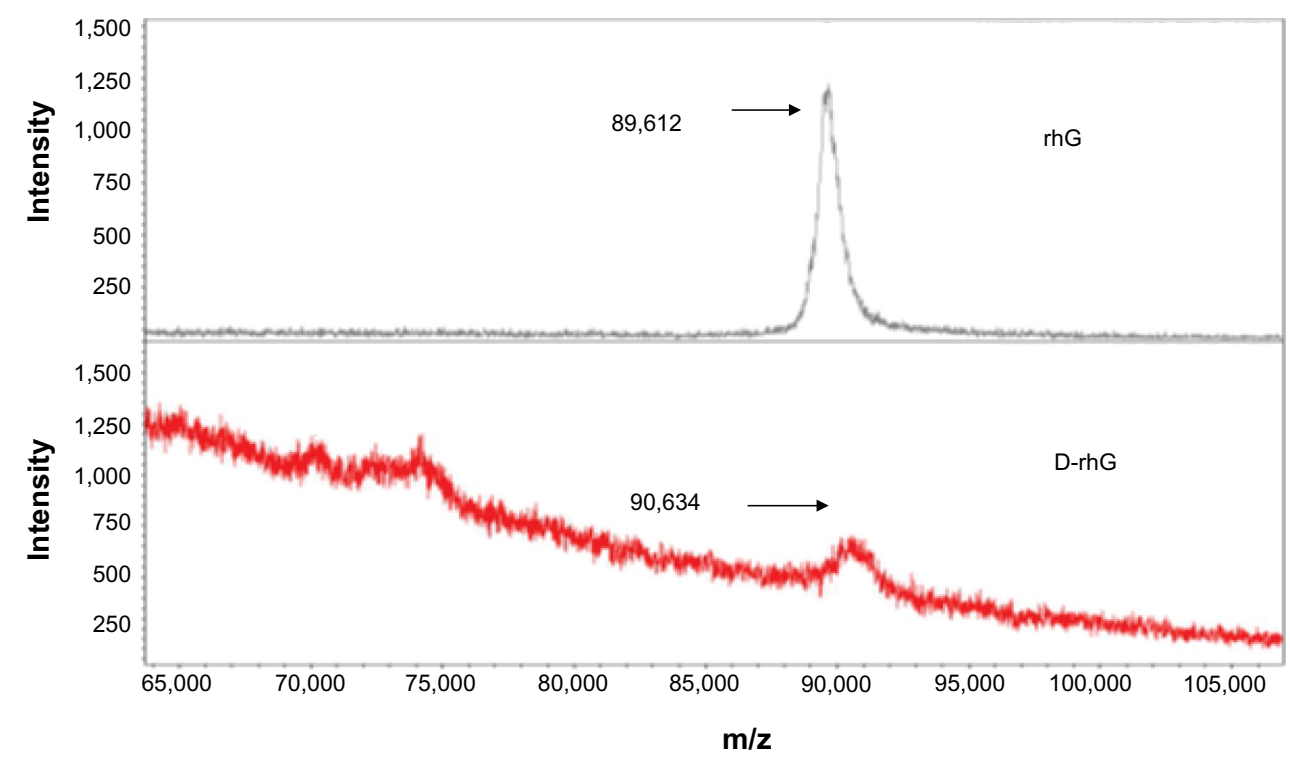

Figure 3 Matrix assisted laser desorption/ionization time-of-flight mass spectra of rhG and D-rhG. The values shown on the left peaks are measured weights. Abbreviations: rhG, recombinant human gelatin; D-rhG, dopamine-coupled human gelatin. 


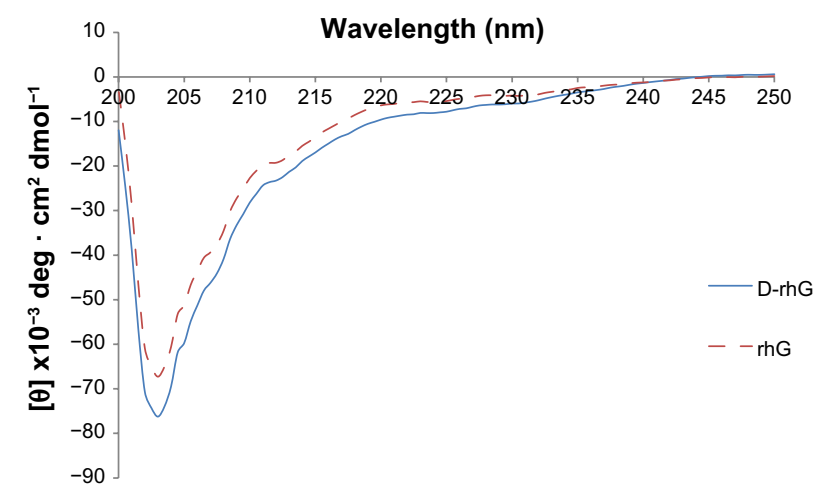

Figure 4 Circular dichroism spectra of rhG (broken line) and D-rhG (solid line). Abbreviations: rhG, recombinant human gelatin; D-rhG, dopamine-coupled human gelatin.

significant conformational changes due to dopamine modification (Figure 4).

\section{Modified gelatin solutions}

The gelatin solutions are shown in Figure 5. Although the color of unmodified gelatin was the same at all $\mathrm{pH}$ values, the color of modified gelatin was $\mathrm{pH}-$ dependent. At higher $\mathrm{pH}$ values, the color was dark yellow. The turbidity of the D-rhG solution also depended on $\mathrm{pH}$ (Figure 6), and was more turbid at higher $\mathrm{pH}$ values. Turbidity increased with time, suggesting molecular aggregation in the solution. A dose-dependent turbidity change was also observed as shown in Figure S1, as observed in dopamine solution (Figure S2). The turbidity of the D-rhG solution was saturated in the range of more than $3 \mathrm{mg} / \mathrm{mL}$ concentration for all $\mathrm{pH}$ conditions, whereas the rhG solution did not show any concentration-dependent change in turbidity in any sample. Surface treatment of modified gelatin was done

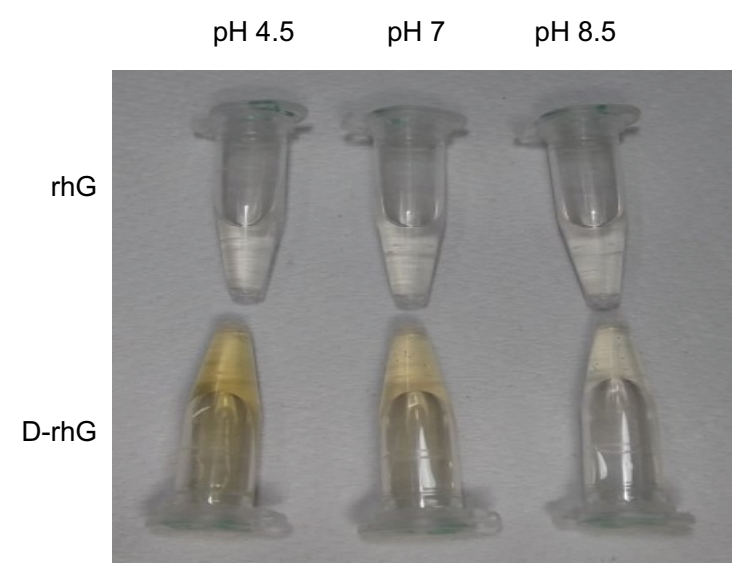

Figure 5 Appearance of rhG and D-rhG at different $\mathrm{pH}$ values.

Abbreviations: rhG, recombinant human gelatin; D-rhG, dopamine-coupled human gelatin.

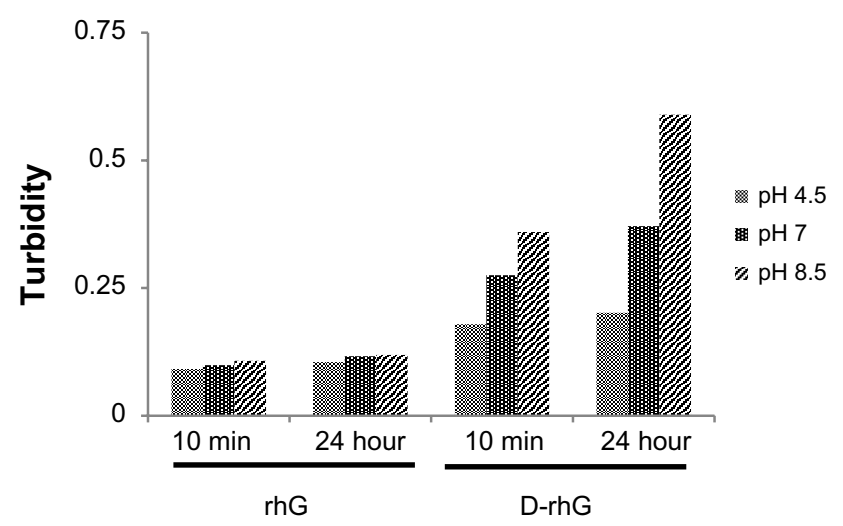

Figure 6 Turbidity of rhG and D-rhG after 10 minutes (min) and 24 hours at different $\mathrm{pH}$ values.

Abbreviations: rhG, recombinant human gelatin; D-rhG, dopamine-coupled human gelatin.

using $3 \mathrm{mg} / \mathrm{mL}$ gelatin solution and the turbidity of the solution correlated with surface binding of D-rhG. These data suggest that incorporation of dopamine and $\mathrm{pH}-$ dependent reactivity changes contributed to D-rhG binding to the titanium surface.

These results are similar to previously reported results for dopamine solutions. ${ }^{32,33}$ It is likely that Michael addition or Schiff base reactions are prevalent in the high-pH dopamine solutions, as reported elsewhere. ${ }^{15}$ Based on this, we concluded that D-rhG has properties similar to those of dopamine. Although the content of dopamine in D-rhG was not very high, conjugation significantly affected the properties of gelatin.

\section{Surface characterizations of D-rhG-coated titanium}

Table 1 shows the results for water contact angle measurements on the treated titanium discs. Treatment with gelatin reduced the hydrophilicity of titanium. Although the effect of rhG was not dependent on $\mathrm{pH}$, the effect of D-rhG was dependent on $\mathrm{pH}$. The water contact angle of the D-rhG

Table I Water contact angle of droplets on rhG-treated or D-rhG-treated titanium surfaces

\begin{tabular}{lll}
\hline Gelatin & Treatment pH & Contact angle (degrees) \\
\hline None & & $9.8 \pm 2.1$ \\
rhG & 4.5 & $25 \pm 4.0$ \\
& 7.0 & $24 \pm 3.6$ \\
& 8.5 & $28 \pm 2.4$ \\
D-rhG & 4.5 & $28 \pm 2.0$ \\
& 7.0 & $34 \pm 1.6$ \\
& 8.5 & $38 \pm 2.1$ \\
\hline
\end{tabular}

Abbreviations: rhG, recombinant human gelatin; D-rhG, dopamine-coupled human gelatin. 


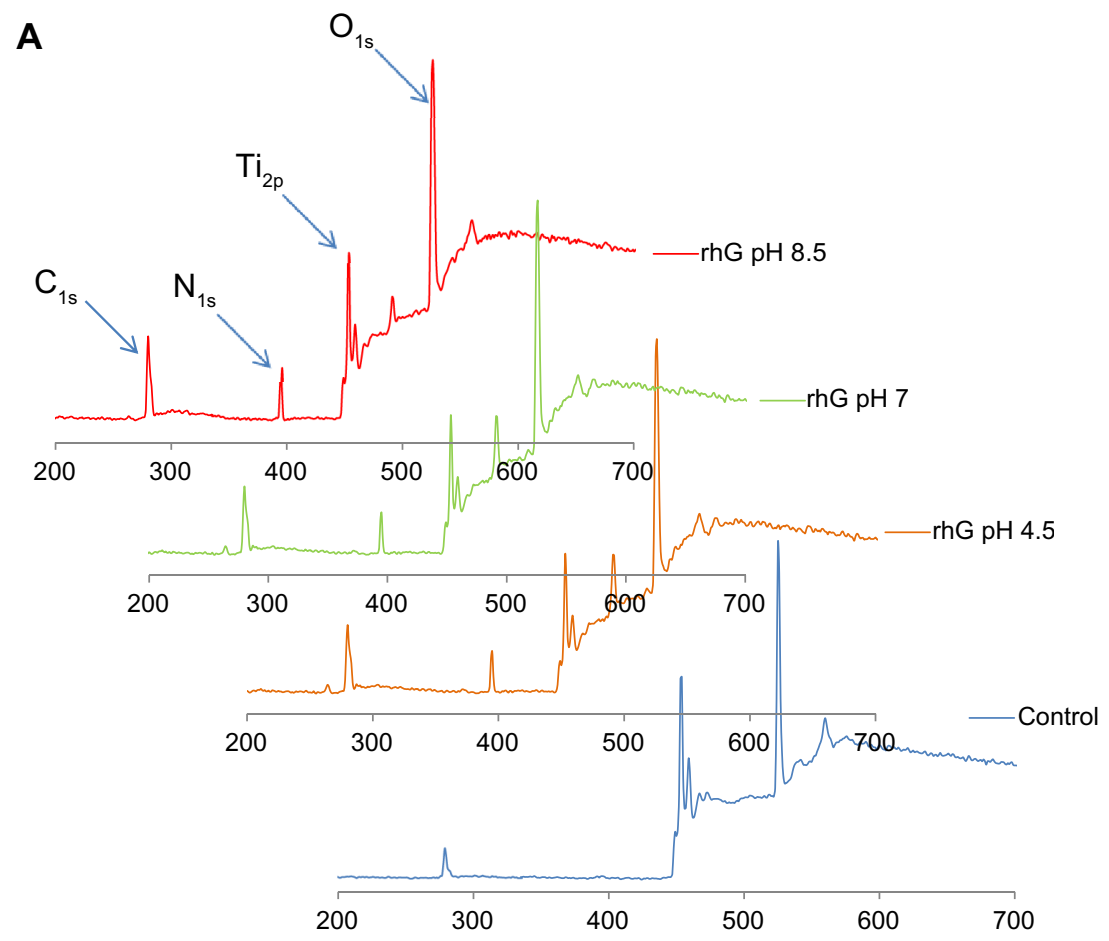

\section{Binding energy (eV)}

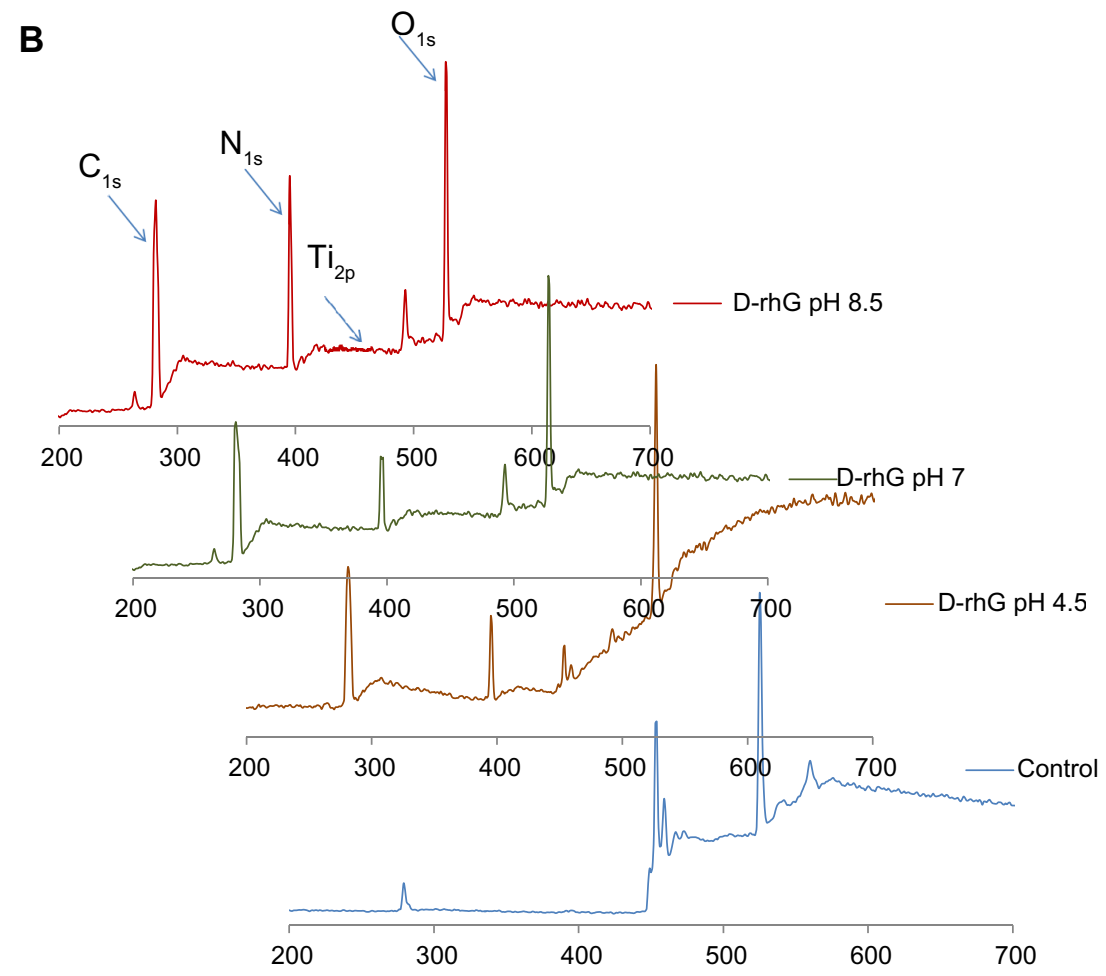

\section{Binding energy (eV)}

Figure $\mathbf{7}$ X-ray photoelectron wide spectra of titanium treated with $(\mathbf{A}) \mathrm{rhG}$ and $(\mathbf{B}) \mathrm{D}$-rhG.

Note: $\mathrm{C}_{1 \mathrm{~s}}, \mathrm{~N}_{1 \mathrm{~s}}, \mathrm{Ti}_{2 \mathrm{p}}$, and $\mathrm{O}_{1 \mathrm{~s}}$ are orbitals of elements, carbon, nitrogen, titanium, and oxygen, respectively.

Abbreviations: rhG, recombinant human gelatin; D-rhG, dopamine-coupled human gelatin; Control, non-coated titanium surface. 
Table 2 X-ray photoelectron spectroscopic analysis of treated surfaces

\begin{tabular}{lllll}
\hline Gelatin & $\begin{array}{l}\text { Treatment } \\
\mathbf{p H}\end{array}$ & \multicolumn{3}{c}{ Peak intensity ratio } \\
\cline { 3 - 5 } & & $\mathbf{C}_{\mathrm{ss}} / \mathbf{T i}_{2 \mathrm{p}}$ & $\mathbf{N}_{\mathrm{ls}} / \mathrm{Ti}_{2 \mathrm{p}}$ & $\mathbf{O}_{\mathbf{1 s}} / \mathbf{T i}_{2 \mathrm{p}}$ \\
\hline None & & 0.14 & 0.02 & 1.14 \\
rhG & 4.5 & 0.56 & 0.35 & 1.67 \\
& 7.0 & 0.56 & 0.36 & 1.67 \\
\multirow{2}{*}{ D-rhG } & 8.5 & 0.60 & 0.38 & 1.52 \\
& 4.5 & 4.10 & 2.71 & 5.50 \\
& 7.0 & 10.75 & 5.60 & 8.50 \\
& 8.5 & 13.44 & 10.31 & 11.18 \\
\hline
\end{tabular}

Note: $\mathrm{C}_{1 \mathrm{~s}}, \mathrm{~N}_{1 \mathrm{~s}}, \mathrm{Ti}_{2 \mathrm{p}}$, and $\mathrm{O}_{1 \mathrm{~s}}$ are orbitals of elements, carbon, nitrogen, titanium, and oxygen, respectively.

Abbreviations: rhG, recombinant human gelatin; D-rhG, dopamine-coupled human gelatin.

treated-surface was highest at $\mathrm{pH} 8.5$, indicating a reduction in surface hydrophilicity.

The chemical composition of the treated surfaces was characterized with X-ray photoelectron spectroscopy, as shown in Figure 7, and the results are summarized in Table 2. Bare titanium plate exhibited mainly titanium and oxygen peaks. After treatment with gelatin, a new nitrogen peak appeared and the carbon peak intensity increased, while the peaks for titanium and oxygen were reduced. These results demonstrate the surface coverage of titanium by gelatin. The relative magnitudes indicate that $\mathrm{D}$-rhG covered more of the surface than rhG and that this coverage was $\mathrm{pH}$-dependent, as shown in Table 2. At higher $\mathrm{pH}$ values, the area of the surface covered by D-rhG was increased.
The mass of bound rhG and D-rhG was measured by quartz crystal microbalance (Figure 8). Although the binding of D-rhG was almost the same as that of $\mathrm{rhG}$ at acidic $\mathrm{pH}$, it was significantly higher than that of $\mathrm{rhG}$ at neutral and basic $\mathrm{pH}$ values. It is likely that $\mathrm{D}-\mathrm{rhG}$, at higher $\mathrm{pH}$ values, bound onto the titanium surface and accumulated with the aggregation of D-rhG in solution (Figure 10C).

This result was also confirmed by thickness measurements using ellipsometry (Figure 9). The measured thicknesses displayed the same order and trends as those calculated from the mass of bound gelatin (Figure 8). The thickness ranged from $5 \mathrm{~nm}$ to $30 \mathrm{~nm}$. The thickness of D-rhG layers formed at $\mathrm{pH} 8.5$ was about four times that formed at $\mathrm{pH} 4.5$ and was about six times as thick as $\mathrm{rhG}$ formed at $\mathrm{pH} 8.5$.

The surface morphology of the titanium discs treated with rhG or D-rhG was observed by atomic force microscopy (Figure 10). The surfaces of the rhG-treated discs at all $\mathrm{pH}$ values (Figure 10A) were as smooth as the nontreated discs. The surface of the discs treated with $\mathrm{D}-\mathrm{rhG}$ at $\mathrm{pH} 4.5$ and 7.0 (Figure 10B) was also mostly smooth, except for several particle-like structures that were possibly protein aggregates. In contrast, the discs treated with D-rhG at $\mathrm{pH} 8.5$ showed long island structures (Figure 10C). The height of these islands was about $20 \mathrm{~nm}$ (top figure of Figure 10C), their width was typically a few microns, and their length was 10-20 $\mu \mathrm{m}$. These islands

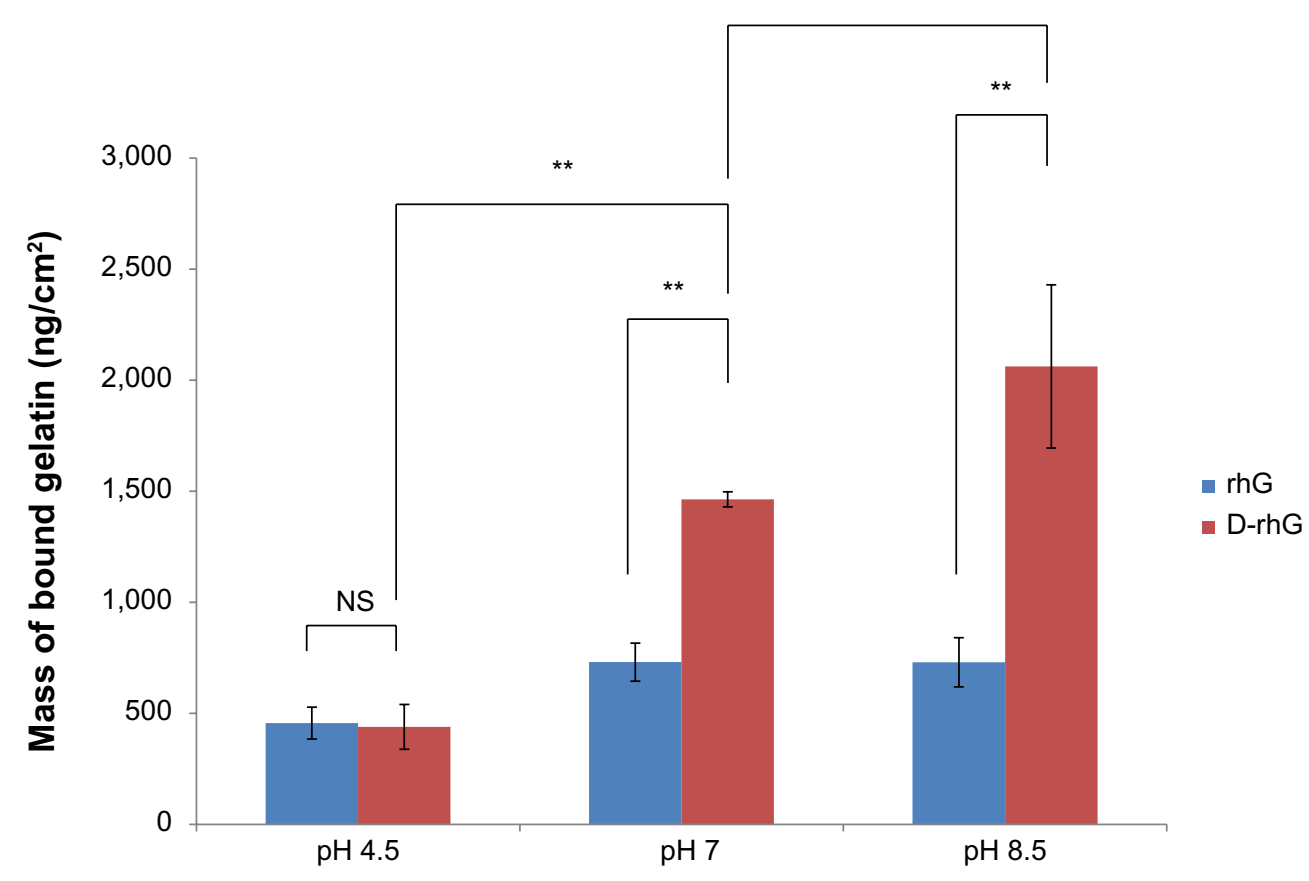

Figure 8 Binding measurement by quartz crystal microbalance at different $\mathrm{pH}$ values. Mean and standard deviation of three experiments. $* \mathrm{P}<0.05$; $* * P<0.0$. Abbreviations: NS, not significant; rhG, recombinant human gelatin; D-rhG, dopamine-coupled human gelatin. 


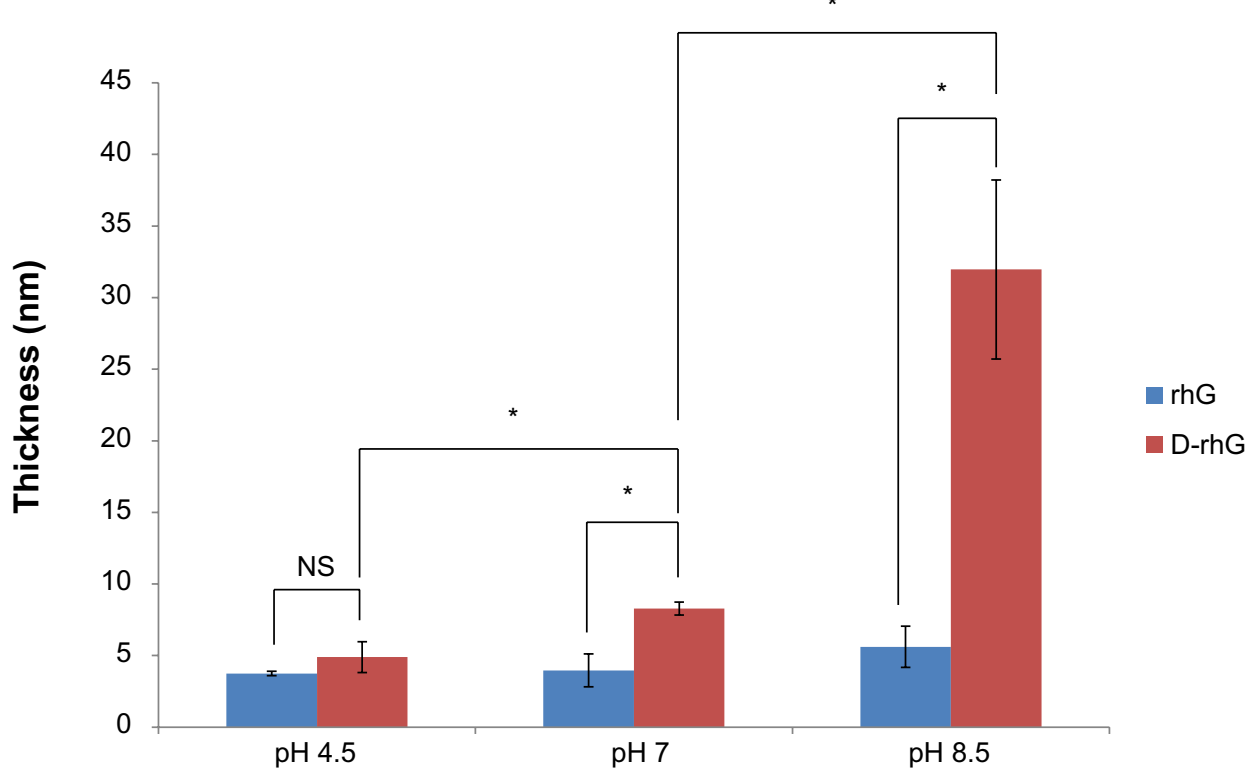

Figure 9 Thickness measured by ellipsometry. The means \pm standard deviations of three experiments are shown. $* P<0.05$. Abbreviations: NS, not significant; rhG, recombinant human gelatin; D-rhG, dopamine-coupled human gelatin.

were also observable by optical microscopy (bottom figure of Figure 10C). The island structures might be related to the high turbidity of the D-rhG solution at pH 8.5 (Figure 6), suggesting aggregation of the protein molecules. A similar $\mathrm{pH}$ dependence was also observed in poly(dopamine) formation. ${ }^{43-46}$

\section{Specific protein binding} on D-rhG coated surface

The capture of collagen binding growth factors is important for the specificity of bound gelatin ${ }^{10}$ and for other tissue engineering applications. ${ }^{47-50}$ Therefore, binding of CBDVEGF onto the gelatin-treated surface was assessed using the anti-VEGF antibody (Figure 11).

Treatment with gelatin increased the binding of CBDVEGF, with higher amounts of gelatin bound at $\mathrm{pH} 8.5$ than at $\mathrm{pH} 4.5$. This result indicates that modification of gelatin by dopamine did not affect the affinity binding of CBD-VEGF, and that binding was principally dependent on the surface concentration of gelatin. D-rhG enhanced CBD-VEGF binding slightly, but significantly more than

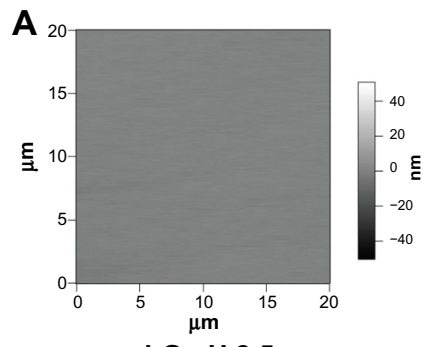

rhG pH 8.5
B

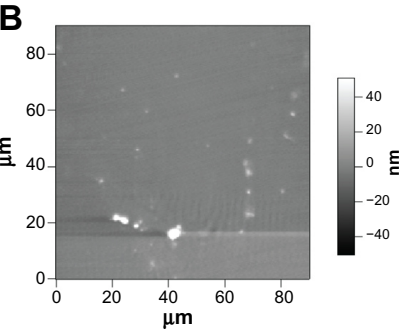

D-rhG pH 7

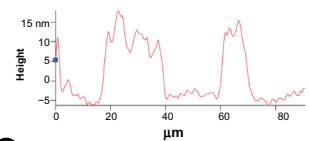

C

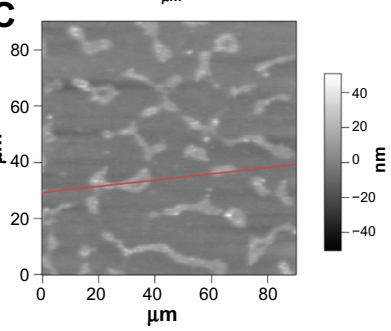

D-rhG pH 8.5

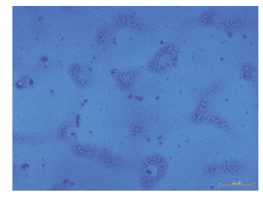

Figure 10 Surface morphology measured by atomic force microscopy. (A) rhG at pH 8.5 (scan size $20 \mu \mathrm{m}$ ), (B) D-rhG at pH 7 (scan size $90 \mu \mathrm{m}$ ), and (C) D-rhG at $\mathrm{pH} 8.5$ (scan size $90 \mu \mathrm{m}$ ). The top figure in $(\mathbf{C})$ is the cross-sectional height profile measured at the red line in the morphology image. The bottom figure in (C) is an optical microscope image of D-rhG at pH 8.5 (scale bar $10 \mu \mathrm{m})$.

Abbreviations: rhG, recombinant human gelatin; D-rhG, dopamine-coupled human gelatin. 


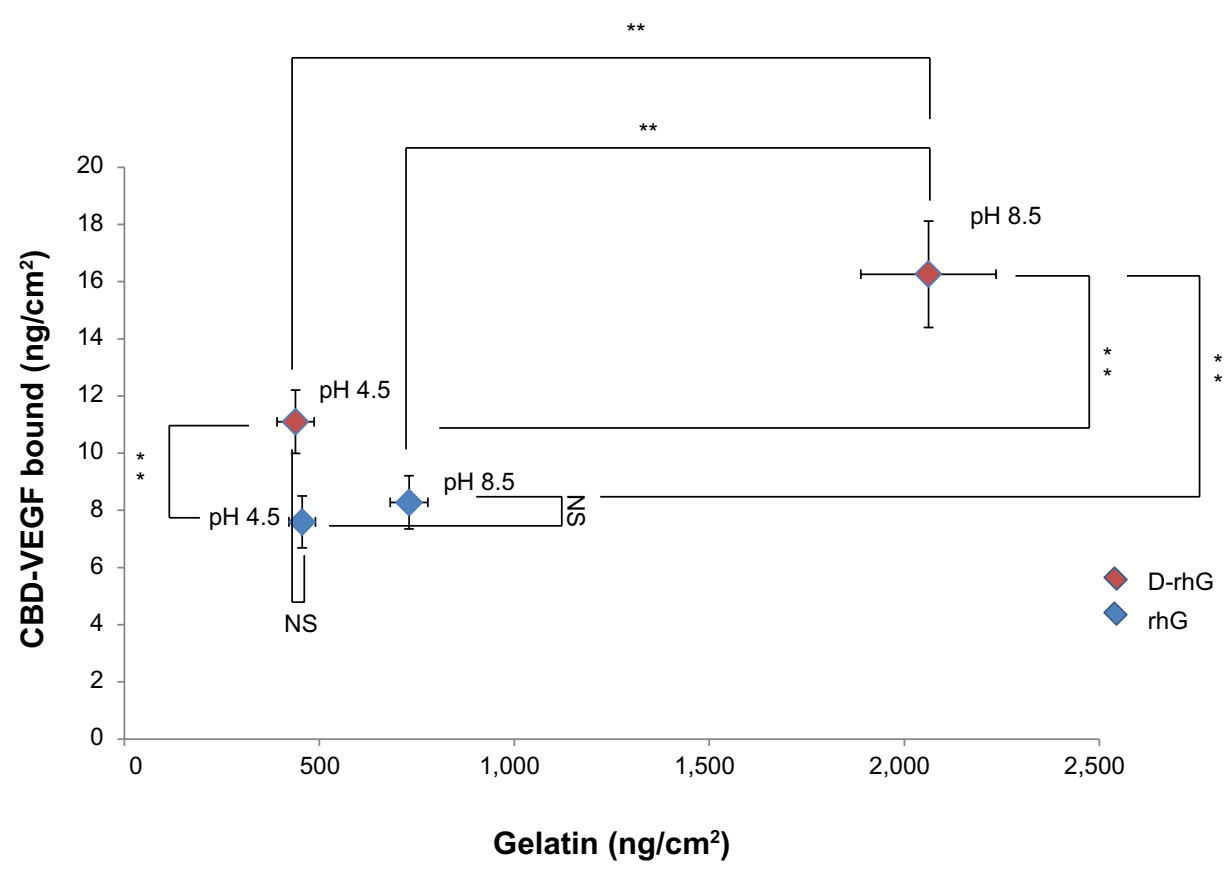

Figure II Binding of CBD-VEGF onto treated titanium at different surface concentrations of rhG or D-rhG. The means \pm standard deviations of three experiments are shown. $* P<0.05 ; * * P<0.01$.

Abbreviations: NS, not significant; rhG, recombinant human gelatin; D-rhG, dopamine-coupled human gelatin; CBD-VEGF, collagen binding domain and vascular endothelial growth factor.

rhG at the same surface concentration at $\mathrm{pH}$ 4.5. This suggests that conjugated dopamine may affect protein adsorption.

\section{Cell attachment and growth}

The effect of immobilized gelatin on cell behavior was examined by incubating HUVECs on the treated surfaces.
Figure 12 shows that bound gelatin enhanced cell attachment, with higher cell attachment on surfaces with more bound gelatin. Additionally, a slight increase in cell binding was observed for D-rhG-treated compared with rhG-treated surfaces at the same surface concentration ( $\mathrm{pH}$ 4.5). Dopamine conjugation may also enhance the attachment of cells, similar to the results obtained for

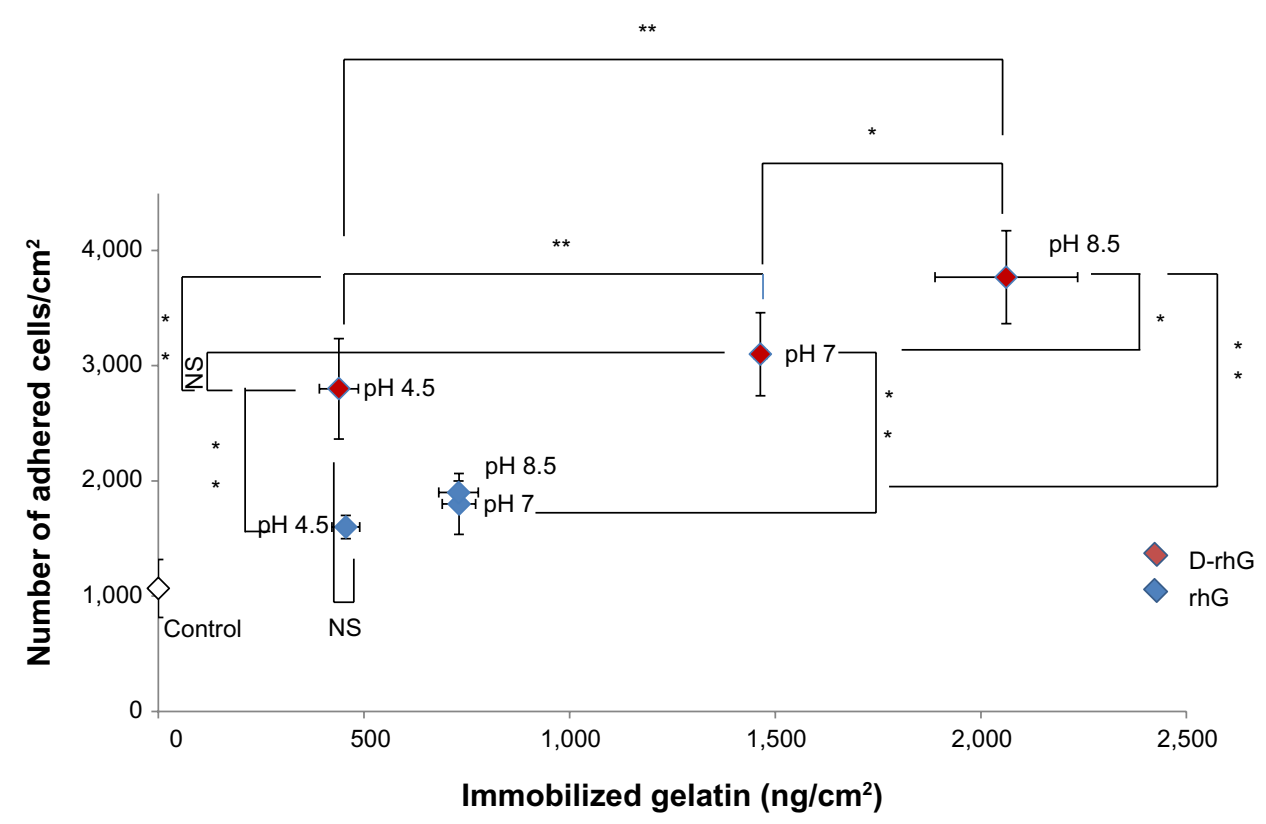

Figure 12 Cell attachment on gelatin-bound titanium surfaces over 30 minutes. The number of human umbilical endothelial cells adhered to the titanium surfaces treated with gelatin at different $\mathrm{pH}$ values was counted. The means \pm standard deviations of five measurements are shown. $* P<0.05 ; * * P<0.01$.

Abbreviations: NS, not significant; rhG, recombinant human gelatin; D-rhG, dopamine-coupled human gelatin. 


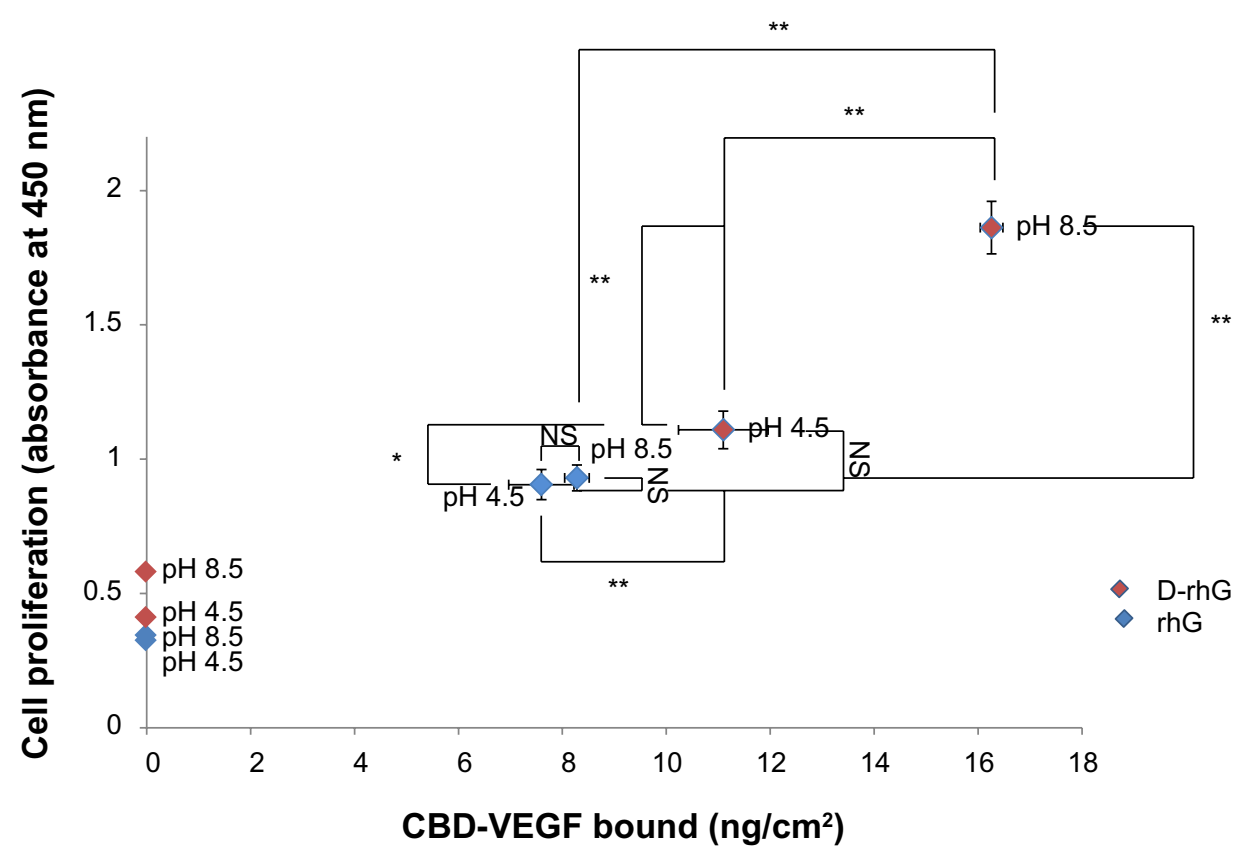

Figure 13 Cell proliferation on gelatin-treated titanium discs with bound CBD-VEGF. The extent of proliferation was assayed using a cell counting kit (absorbance at $450 \mathrm{~nm}$ ). The means \pm standard deviations of three experiments are shown. $* P<0.05 ; * * P<0.01$.

Abbreviations: NS, not significant; CBD-VEGF, collagen binding domain and vascular endothelial growth factor.

protein binding, where the poly(dopamine)-treated surface was observed to enhance cell adhesion because of the catechol moieties. $^{51}$

Figure 13 shows the increase in growth of HUVECs on gelatin-treated titanium discs with CBD-VEGF. Even without CBD-VEGF, cells grew to some extent on the D-rhG-treated and rhG-treated surfaces. The presence of CBD-VEGF captured by gelatin significantly enhanced cell growth. In particular, the surfaces treated with D-rhG at high $\mathrm{pH}$ showed remarkable cell growth. In summary, dopamine conjugation enhanced cell attachment to and growth on titanium discs via efficient surface coating, likely due to the catechol moieties ${ }^{51}$ and the specific affinity binding of growth factor fusion protein.

\section{Conclusion}

The binding affinity of human recombinant gelatin to a titanium surface was significantly enhanced by conjugation with dopamine. The bound gelatin directly enhanced cell attachment. The D-rhG-coated surface is suitable for the capture and sequestering of a specific growth factor that supports cell proliferation. We conclude that this mussel-inspired dopamine modification is an effective method for preparation of adhesive materials and the gelatin application described here may be useful for human cell culture systems and other tissue engineering applications.

\section{Acknowledgment}

This work was supported in part by a grant from the Japanese Society for Promotion of Science Grants-in-Aid for Scientific Research (22220009).

\section{Disclosure}

The authors report no conflicts of interest in this work.

\section{References}

1. Lai JY, Lu PL, Chen KH, Tabata Y, Hsiue GH. Effect of charge and molecular weight on the functionality of gelatin carriers for corneal endothelial cell therapy. Biomacromolecules. 2006;7(6):1836-1844.

2. Lai JY, Li YT. Functional assessment of cross-linked porous gelatin hydrogels for bioengineered cell sheet carriers. Biomacromolecules. 2010;11(5):1387-1397.

3. Olsen D, Yang CL, Bodo M, et al. Recombinant collagen and gelatin for drug delivery. Adv Drug Deliv Rev. 2003;55(12):1547-1567.

4. Olsen D, Jiang J, Chang R, et al. Expression and characterization of a low molecular weight recombinant human gelatin: development of a substitute for animal-derived gelatin with superior features. Protein Expr Purif. 2005;40(2):346-357.

5. Duan HM, Umar S, Xiong RS, Chen JC. New strategy for expression of recombinant hydroxylated human-derived gelatin in pichia pastoris KM71. J Agric Food Chem. 2011;59(13):7127-7134.

6. Shoseyov O, Posen Y, Grynspan F. Human recombinant type I collagen produced in plants. Tissue Eng Pt A. 2013;19(13-14):1527-1533.

7. Adachi T, Wang XB, Murata T, et al. Production of a non-triple helical collagen alpha chain in transgenic silkworms and its evaluation as a gelatin substitute for cell culture. Biotechnol Bioeng. 2010;106(6): 860-870.

8. Kadengodlu PA, Hebishima T, Takeshima SN, et al. Positively charged cholesterol-recombinant human gelatins foster the cellular uptake of proteins and murine immune reactions. Int $J$ Nanomedicine. 2012;7:5437-5450. 
9. Kadengodlu PA, Aigaki T, Abe H, Ito Y. Cationic cholesterolmodified gelatin as an in vitro siRNA delivery vehicle. Mol Biosyst. 2013;9(5):965-968.

10. Kitajima T, Obuse S, Adachi T, Tomita M, Ito Y. Recombinant human gelatin substitute with photoreactive properties for cell culture and tissue engineering. Biotechnol Bioeng. 2011;108(10): 2468-2476.

11. Li Z, Kawashita M. Current progress in inorganic artificial biomaterials. J Artif Organs. 2011;14(3):163-170.

12. Zhou D, Ito Y. Inorganic material surfaces made bioactive by immobilizing growth factors for hard tissue engineering. RSC $A d v$. 2013;3(28):11095-11106.

13. Byern J, Grunwald I. Biological Adhesive Systems. 1st ed. Wien, Germany: Springer Verlag; 2010.

14. Lee BP, Messersmith PB, Israelachvili JN, Waite JH. Mussel-inspired adhesives and coatings. Annu Rev Mater Res. 2011;41:99-132.

15. Lee H, Dellatore SM, Miller WM, Messersmith PB. Mussel-inspired surface chemistry for multifunctional coatings. Science. 2007; 318(5849):426-430.

16. Harrington MJ, Masic A, Holten-Andersen N, Waite JH, Fratzl P. Iron-clad fibers: a metal-based biological strategy for hard flexible coatings. Science. 2010;328(5975):216-220.

17. Hwang DS, Waite JH, Tirrell M. Promotion of osteoblast proliferation on complex coacervation-based hyaluronic acid - recombinant mussel adhesive protein coatings on titanium. Biomaterials. 2010;31(6): 1080-1084.

18. Choi BH, Choi YS, Kane DG, Kim BJ, Song YH, Cha HJ. Cell behavior on extracellular matrix mimic materials based on mussel adhesive protein fused with functional peptides. Biomaterials. 2010;31(34):8980-8988.

19. Xu CJ, Xu KM, Gu HW, et al. Dopamine as a robust anchor to immobilize functional molecules on the iron oxide shell of magnetic nanoparticles. J Am Chem Soc. 2004;126(32):9938-9939.

20. He T, Shi ZL, Fang N, Neoh KG, Kang ET, Chan V. The effect of adhesive ligands on bacterial and fibroblast adhesions to surfaces. Biomaterials. 2009;30(3):317-326.

21. Ju KY, Lee Y, Lee S, Park SB, Lee JK. Bioinspired polymerization of dopamine to generate melanin-like nanoparticles having an excellent free-radical-scavenging property. Biomacromolecules. 2011;12(3):625-632.

22. Fan XW, Lin LJ, Messersmith PB. Cell fouling resistance of polymer brushes grafted from Ti substrates by surface-initiated polymerization: effect of ethylene glycol side chain length. Biomacromolecules. 2006;7(8):2443-2448.

23. Wach JY, Malisova B, Bonazzi S, et al. Protein-resistant surfaces through mild dopamine surface functionalization. Chemistry. 2008; 14(34):10579-10584.

24. Yuan S, Wan D, Liang B, et al. Lysozyme-coupled poly(poly(ethylene glycol) methacrylate)-stainless steel hybrids and their antifouling and antibacterial surfaces. Langmuir. 2011;27(6): 2761-2774.

25. Ku SH, Ryu J, Hong SK, Lee H, Park CB. General functionalization route for cell adhesion on non-wetting surfaces. Biomaterials. 2010; 31(9):2535-2541.

26. Yang SH, Kang SM, Lee KB, Chung TD, Lee H, Choi IS. Musselinspired encapsulation and functionalization of individual yeast cells. J Am Chem Soc. 2011;133(9):2795-2797.

27. Ku SH, Lee JS, Park CB. Spatial control of cell adhesion and patterning through mussel-inspired surface modification by polydopamine. Langmuir. 2010;26(19):15104-15108.

28. Lynge ME, Ogaki R, Laursen AO, Lovmand J, Sutherland DS, Stadler B. Polydopamine/liposome coatings and their interaction with myoblast cells. ACS Appl Mater Interfaces. 2011;3(6):2142-2147.

29. Zhou WH, Lu CH, Guo XC, Chen FR, Yang HH, Wang XR. Mussel-inspired molecularly imprinted polymer coating superparamagnetic nanoparticles for protein recognition. $J$ Mater Chem. 2010;20: 880-883.
30. Lee H, Rho J, Messersmith PB. Facile conjugation of biomolecules onto surfaces via mussel adhesive protein inspired coatings. Adv Mater. 2009;21(4):431-434.

31. Wei Q, Li BJ, Yi N, et al. Improving the blood compatibility of material surfaces via biomolecule-immobilized mussel-inspired coatings. J Biomed Mater Res A. 2011;96A(1):38-45.

32. Kang J, Sakuragi M, Shibata A, et al. Immobilization of epidermal growth factor on titanium and stainless steel surfaces via dopamine treatment. Mat Sci Eng C. 2012;32(8):2552-2561.

33. Kang J, Tada S, Kitajima T, Son TI, Aigaki T, Ito Y. Immobilization of bone morphogenetic protein on DOPA- or dopamine-treated titanium surfaces to enhance osseointegration. BioMed Res Int. 2013;2013: 265980.

34. Lee Y, Lee H, Kim YB, et al. Bioinspired surface immobilization of hyaluronic acid on monodisperse magnetite nanocrystals for targeted cancer imaging. Adv Mater. 2008;20(21):4154-4157.

35. You I, Kang SM, Byun Y, Lee H. Enhancement of blood compatibility of poly(urethane) substrates by mussel-inspired adhesive heparin coating. Bioconjug Chem. 2011;22(7):1264-1269.

36. Bae IH, Park IK, Park DS, Lee H, Jeong MH. Thromboresistant and endothelialization effects of dopamine-mediated heparin coating on a stent material surface. J Mater Sci Mater Med. 2012;23(5): $1259-1269$.

37. Jung YS, Jeong JH, Yook S, et al. Surface modification of pancreatic islets using heparin-DOPA conjugate and anti-CD154 mAb for the prolonged survival of intrahepatic transplanted islets in a xenograft model. Biomaterials. 2012;33(1):295-303.

38. Yang L, Shi Y, Chen J, Rong L, Yang W. Functional surface modification of PE film by dopamine- $\beta$-cyclodextrin conjugate. $J$ Control Release. 2011;152:e109-e111.

39. Ishikawa T, Eguchi M, Wada M, et al. Establishment of a functionally active collagen-binding vascular endothelial growth factor fusion protein in situ. Arterioscler Thromb Vasc Biol. 2006;26(9): 1998-2004.

40. Ito Y, Hasuda H, Sakuragi M, Tsuzuki S. Surface modification of plastic, glass and titanium by photoimmobilization of polyethylene glycol for antibiofouling. Acta Biomater. 2007;3(6):1024-1032.

41. Heydari M, Hasuda H, Sakuragi M, Yoshida Y, Suzuki K, Ito Y. Modification of the titan surface with photoreactive gelatin to regulate cell attachment. J Biomed Mater Res A. 2007;83A(4): 906-914.

42. Ishiyama M, Miyazono Y, Sasamoto K, Ohkura Y, Ueno K. A highly water-soluble disulfonated tetrazolium salt as a chromogenic indicator for NADH as well as cell viability. Talanta. 1997;44(7): 1299-1305.

43. Shin YM, Lee YB, Kim SJ. Mussel-inspired immobilization of vascular endothelial growth factor (VEGF) for enhanced endothelialization of vascular grafts. Biomacromolecules. 2012;13(7):2020-2028.

44. Nirasay S, Badia A, Leclair G, Claverie JP, Marcotte I. Polydopaminesupported lipid bilayers. Materials. 2012;5:2621-2636.

45. Zangmeister RA, Morris TA, Tarlov MJ. Characterization of polydopamine thin films deposited at short times by autoxidation of dopamine. Langmuir. 2013;29(27):8619-8628.

46. Shalev T, Gopin A, Bauer M, Stark RW, Rahimipour S. Non-leaching antimicrobial surfaces through polydopamine bio-inspired coating of quaternary ammonium salts or an ultrashort antimicrobial lipopeptide. J Mater Chem. 2012;22:2026.

47. Kitajima T, Terai H, Ito Y. A fusion protein of hepatocyte growth factor for immobilization to collagen. Biomaterials. 2007;28(11): 1989-1997.

48. Ota T, Gilbert TW, Schwartzman D, et al. A fusion protein of hepatocyte growth factor enhances reconstruction of myocardium in a cardiac patch derived from porcine urinary bladder matrix. JThorac Cardiovasc Surg. 2008;136(5):1309-1317.

49. Lu H, Kawazoe N, Kitajima T, et al. Spatial immobilization of bone morphogenetic protein-4 in a collagen-PLGA hybrid scaffold for enhanced osteoinductivity. Biomaterials. 2012;33(26):6140-6146. 
50. Shiozaki Y, Kitajima T, Mazaki T, et al. Enhanced in vivo osteogenesis by nanocarrier-fused BMP4. Int J Nanomedicine. 2013;8: 1349-1360.
51. Ku SH, Park CB. Human endothelial cell growth on mussel-inspired nanofiber scaffold for vascular tissue engineering. Biomaterials. 2010;31(36):9431-9437. 


\section{Supplementary materials}

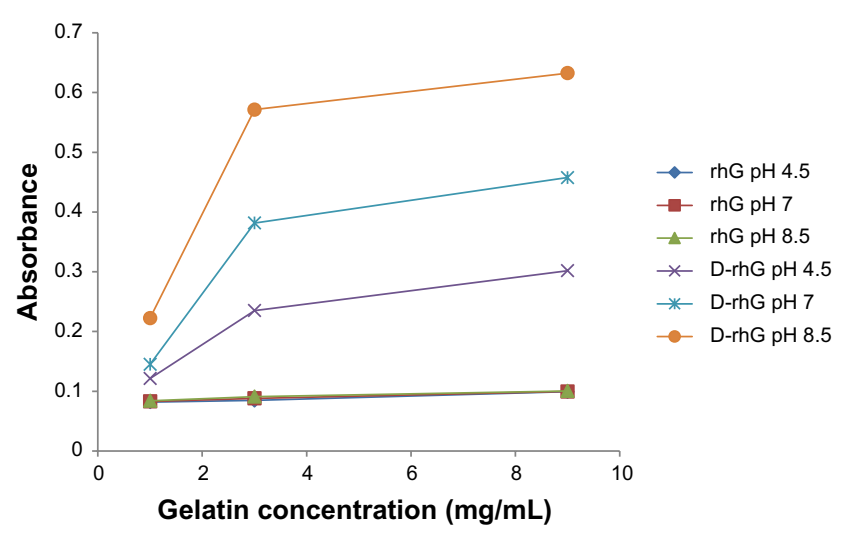

Figure SI Dose-dependent turbidity of solutions of rhG and D-rhG at different $\mathrm{pH}$ values.

Abbreviations: rhG, recombinant human gelatin; D-rhG, dopamine-coupled human gelatin.

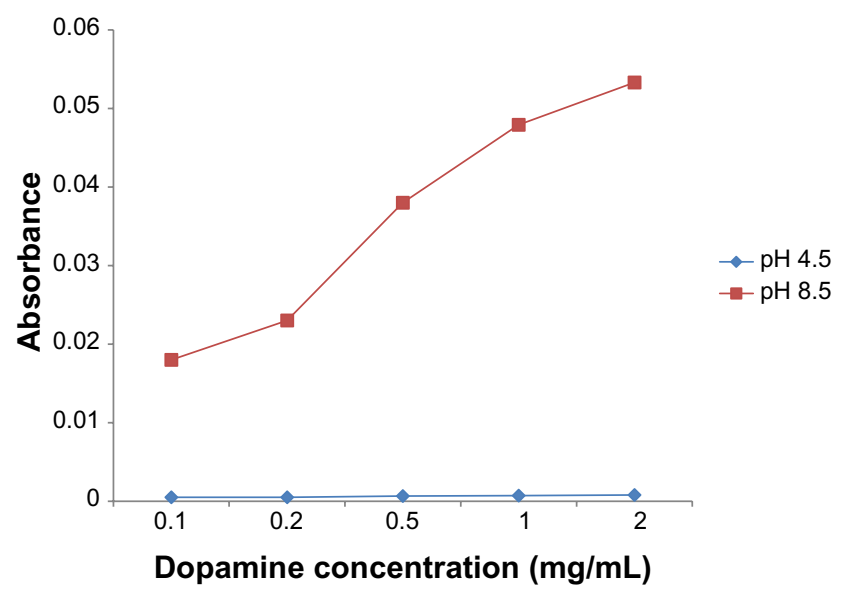

Figure S2 Turbidity of dopamine solutions at different concentrations.
International Journal of Nanomedicine

\section{Publish your work in this journal}

The International Journal of Nanomedicine is an international, peerreviewed journal focusing on the application of nanotechnology in diagnostics, therapeutics, and drug delivery systems throughout the biomedical field. This journal is indexed on PubMed Central,

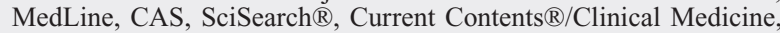

\section{Dovepress}

Journal Citation Reports/Science Edition, EMBase, Scopus and the Elsevier Bibliographic databases. The manuscript management system is completely online and includes a very quick and fair peer-review system, which is all easy to use. Visit http://www.dovepress.com/ testimonials.php to read real quotes from published authors. 